\title{
Possible Therapeutic Role of Mesenchymal Stem Cells on Colostomy Induced Myenteric Plexus Histological Changes in Different GIT Levels in Adult Male Albino Rats: Histological and Immunohistochemical Study
}

Samah M Ahmed* and Dalia A Mohamed

Department of Histology and Cell Biology, Zagazig University, Zagazig, Egypt

\begin{abstract}
Enteric Nervous System (ENS) is of special interest as it is the only substantial grouping of neurons outside the CNS. ENS alterations participate in the motility disorders. Colostomy is a lifesaving surgery that treats many diseases and problems. The aim of this study was designed to investigate the histological changes that could occur in the myenteric plexus in case of colostomy and to evaluate the therapeutic role of mesenchymal stem cell. Thirty five healthy adult Wistar male albino rats were classified into three groups: Group1 (control) was equally subdivided into negative control (1a), sham operated-untreated (1b) and vehicle-treated subgroups (1c). Group2 (colostomy group): subjected to colostomy operation. Group3 (BM-MSCs-treated group): subjected to colostomy operation and then treated with undifferentiated BM-MSCs. At the end of the experiment, the rats were sacrificed and specimens from different levels of GIT were prepared for histological and immunohistochemical examination. The results were histomorphometrically and statistically analyzed. Light microscope examination of Group2 showed irregular connective tissue capsule of myenteric plexus in different GIT levels. The neurons and glial cells appeared small in size, irregular in shape with separation between the cells. In Group3, the same levels preserved normal myenteric plexuses structure. Immunoperoxidase reaction for synaptophysin revealed weak positive immunoreaction in the colostomy group that returned moderate to strong positive reaction in BM-MSCs-treated group. Additionally, fluorescent microscope examination revealed PKH26 labled cells that appeared as bright red dots in the myenteric plexuses between smooth muscle fibers in BM-MSCs-treated group. In conclusion, colostomy adversely affected the histological structure of myenteric plexus in different GIT levels. Mesenchymal stem cell therapy could be promising as an adjuvant treatment for rescuing ENS in case of colostomy.
\end{abstract}

Keywords: Colostomy; Albino rats; Mesenchymal stem cells; Histology; Synaptophysin

Abbreviations: ENS: Enteric Nervous System; GIT: Gastrointestinal Tract; IPA: Intrinsic Primary Afferent; IPAN: Interneurones Primary Afferent; IBD: Inflammatory Bowel Diseases; EGC: Enteric Glial Cell; MSCs: Mesenchymal Stem Cells; TA: Transient Amplifying

\section{Introduction}

Digestive functions are regulated by a complex neuronal network called ENS. It rivals the brain in its complexity and can function independently. Initiation and regulation of small-bowel function depends on its normal function. ENS is considered the largest and the most complex subdivision of peripheral nervous system $[1,2]$.

ENS is an integrative network of neurons and glial cells within nerve fibers that distributed along the whole length of gastrointestinal tract. It is organized in two major ganglionated plexuses; myenteric (Auerbach's) plexus and submucosal (Meissner's) plexus. Both are made of various types of cells including functionally different neurons and Enteric Glial Cells (EGC). There are three classes of enteric neurons in the ENS; motor, Intrinsic Primary Afferent (IPA or sensory) and interneurons. Sensory neuron (IPAN) is the primary sensor and regulator of the ENS that detects the chemical features of luminal contents and the physical state of GIT. This cell connects with each other and with motor one by interneuron. Motor neuron is either excitatory or inhibitory $[1,3]$.

Additionally, ENS contains a large population of glial cells that functions as brain astroglia. EGC represent the most abundant nonneuronal cells within this system. These cells have significant role in forming diffusion barrier around the capillaries similar to the blood- brain barrier. EGC are related to interstitial cell of Cajal and electrically coupled to it [2].

Colostomy surgery is done for many people in different GIT diseases and problems. Sometimes, it is only needed for a short time, but for some people it's life-long. Thousands of people have serious digestive diseases; a colostomy can be their start of new and healthy life [4].

Colostomy is a change in the way your body works as it allow the stool to pass after a disease or injury. It is performed as the first step in multistage procedures for congenital abnormalities, in colorectal surgery to prevent anastomotic leakage, or as an emergency procedure in a life-threatening disease [5].

Temporary ostomies can be closed after the resolution of the underlying disease process while, permanent ones are created to be permanent. The majority of indications are gastrointestinal malignancies and Inflammatory Bowel Diseases (IBD) like ulcerative

*Corresponding author: Samah Mohamed Ahmed, Lecturer of Histology and Cell Biology, Faculty of Medicine, Zagazig University, Zagazig, Egypt, Tel: 00201006427658; E-mail: dr_samah_m@yahoo.com

Received August 04, 2016; Accepted September 06, 2016; Published September 12, 2016

Citation: Ahmed SM, Mohamed DA (2016) Possible Therapeutic Role of Mesenchymal Stem Cells on Colostomy Induced Myenteric Plexus Histological Changes in Different GIT Levels in Adult Male Albino Rats: Histological and Immunohistochemical Study. J Stem Cell Res Ther 6: 360. doi: 10.4172/21577633.1000360

Copyright: (c) 2016 Ahmed SM, et al. This is an open-access article distributed under the terms of the Creative Commons Attribution License, which permits unrestricted use, distribution, and reproduction in any medium, provided the original author and source are credited. 
Citation: Ahmed SM, Mohamed DA (2016) Possible Therapeutic Role of Mesenchymal Stem Cells on Colostomy Induced Myenteric Plexus Histological Changes in Different GIT Levels in Adult Male Albino Rats: Histological and Immunohistochemical Study. J Stem Cell Res Ther 6: 360. doi: 10.4172/2157-7633.1000360

Page 2 of 9

colitis, Crohn's disease and etc. [6]. Creation of an ostomy leads to various physiological, psychological and social patients problems. Some studies reported that altered perception of body image, diminished selfesteem, sexual dysfunction, marital problems and various psychiatric conditions, including depression are the most commonly side effects seen with colostomy [7]. Also, GIT complications such as constipation, anorexia and may be hernia could be happened [8].

The inner epithelial lining of stomach and intestine is the most rapidly renewing tissue in our body. The epithelium of the intestine is shaped into small pits called Crypts. Cell renewal is fuelled by stem cells residing in the depth of the crypts. The stem cells produce proliferative progeny called Transient Amplifying (TA) cells or progenitors [9]. It is well known that GIT epithelia renew continuously and can regenerate after injury as long as their stem cells are not destroyed. Stem cells are large primitive cells that do not express markers of lineage differentiation [10].

Several studies reported that stem cells have a significant role in treatment of GIT cancer and explained that GIT cancer may include mutation of their stem cells lying in the crypts. In recent years, efforts have increasingly focused on the study and use of cell therapies with both hematopoietic and Mesenchymal Stem Cells (MSCs) [11].

Few studies discussed the underlying GIT structural changes that occurred after colostomy. So, this study aimed to investigate the underlying histological changes that could be occurred in myenteric plexus in different GIT levels after colostomy. Moreover it evaluates the role of stem cells in improving these changes.

\section{Materials and Methods}

\section{Animals}

Thirty five healthy adult Wistar male albino rats (3-5 months) weighing 220-250 gm. were used in this study. The animals were purchased from the Animal House, Faculty of Medicine, Zagazig University, Zagazig, Egypt. They were fed standard balanced diet and allowed water ad-libitum. They were housed in hygienic cages at room temperature $\left(22 \pm 2^{\circ} \mathrm{C}\right)$ according to the guidelines for animal research issued by the National Institute of Health and approved by Animal Ethics Committee, Zagazig University, Zagazig, Egypt.

\section{Chemicals}

- Povidone -Iodine: Antiseptic solution (B-SEPT), from SAGA PHARMA, Egypt.

- Benzyl Penicillin: In the form of vials containing 1000000 IU Penicillin G, purchased from Misr Company for Pharmaceuticals Industry, Egypt. The vial was dissolved for intramuscular injection using ampoules containing $5 \mathrm{ml}$. water for injection from Egypt Otsuka Pharm co., Egypt.

- Dulbecco's modified Eagle's medium (DMEM, GIBCO/BRL).

- $10 \%$ fetal bovine serum (GIBCO/BRL).

- Density gradient [Ficoll/Paque (Pharmacia)].

- Complete culture medium supplemented with $1 \%$ penicillinstreptomycin (GIBCO/BRL).

- $0.25 \%$ trypsin in $1 \mathrm{~m}$ M EDTA (GIBCO/BRL).

- Phosphate buffer saline (PBS) (GIBCO/BRL).

\section{Surgical procedure (colostomy)}

Surgical procedures were conducted under complete aseptic conditions in the central laboratory, Faculty of Medicine, Zagazig University, Zagazig, Egypt [12]. Rats were submitted to 12-hour fasting with exclusive use of water. Immediately before surgery, a retrograde intestinal wash was performed with saline to remove all fecal matter. Anesthesia was obtained using pentobarbital $(20 \mathrm{mg} / \mathrm{Kg}$ intraperitoneal $)$ and ketamine $(50 \mathrm{mg} / \mathrm{Kg}$ intramuscular). Rats were allowed to breath spontaneously throughout the experiment. They were fixed in dorsal decubitus; shaving and cleaning the lower abdomen using povidoneiodine were performed [13]. The abdominal cavity was opened by a median laparotomy of around $5 \mathrm{~cm}$ to identify the cecum and proximal colon which was divided $5 \mathrm{~cm}$ from the ileocecal valve. The distal colon was submitted to terminal suture. After its sectioning, the distal colonic segment was kept inside the abdominal cavity. The proximal segment was colostomized and exteriorized through the abdominal wall left of the median incision. A single-barreled end colostomy was performed along with fixation of the stoma to the abdominal wall with a 6-0 polypropylene thread. The abdominal wall was then closed with separate 3-0 cotton sutures. For post-surgical care, the surgical wound of the operated rats was cleaned with povidone iodine twice a day. Rats were administered intramuscular benzyl penicillin $0.05 \mathrm{~cm}$ twice a day for 7 days [12,14].

\section{Isolation of BM-MSCs}

Modified from Althadlaq and Mao [15] and Zhang et al. [16], all the following steps were done under complete aseptic conditions. Bone marrow was obtained by flushing the tibiae and femurs of the rats with Dulbecco's modified Eagle's medium (DMEM, GIBCO/BRL) supplemented with $10 \%$ fetal bovine serum (GIBCO/BRL). A dispersed bone marrow cell suspension was washed with phosphate buffer saline (PBS) (GIBCO/BRL) and centrifuged twice and the resulted pellet was diluted with PBS. Mononuclear cells were isolated with a density gradient Ficoll/Paque (Pharmacia). The mononuclear cells were washed and then centrifuged at 2000 RPM for 5 min twice. The pellet obtained was resuspended in high glucose DMEM, $4.5 \mathrm{~g} / \mathrm{L}$ glucose with L-glutamine, (GIBCO/BRL) containing 10\% FBS, supplemented with $1 \%$ penicillin-streptomycin (GIBCO/BRL). Cells were cultured at concentration of $5 \times 10^{6}$ per $25-\mathrm{cm}^{2}$ culture flask, and incubated at $37^{\circ} \mathrm{C}$ in $5 \%$ humidified $\mathrm{CO}_{2}$ in $\mathrm{CO} 2$ incubator (Heraeus, Germany). The media were changed every 3-4 days (to remove non adherent cells) for 12-14 days as primary culture. When large colonies developed (80-90\% confluence), the adherent cells were detached by trypsinization with $0.25 \%$ trypsin/ Ethylene Diamine Tetra Acetic Acid (EDTA) and then were re-plated. Second passage cells were used for the experiment. Cell viability was determined by means of trypan blue staining [17].

Labeling of stem cells with Paul Karl Horan 26 (PKH-26) (red fluorescence cell linker): MSCs were harvested during the 2nd passage and were labeled with PKH26 dye [18]. Cells were centrifuged and washed twice in serum free medium. Cells were pelleted and suspended in dye solution.

Injection of bone marrow-derived mesenchymal stem cells into the rats: Formed colonies of the 2 nd generation were washed twice with PBS and cells were trypsinized with $0.25 \%$ trypsin in $1 \mathrm{mM}$ EDTA for $5 \mathrm{~min}$ at $37^{\circ} \mathrm{C}$. After centrifugation at $2400 \mathrm{RPM}$ for $20 \mathrm{~min}$, cells were counted under microscope by using haemocytometer and a calculated MSCs $\left(1 \times 10^{6}\right.$ cells/ $\left.0.5 \mathrm{ml}\right)$, suspended in PBS, were injected in the tail vein of group 3 rats.

Detection of homing of stem cells: Sections were examined by 
Citation: Ahmed SM, Mohamed DA (2016) Possible Therapeutic Role of Mesenchymal Stem Cells on Colostomy Induced Myenteric Plexus Histological Changes in Different GIT Levels in Adult Male Albino Rats: Histological and Immunohistochemical Study. J Stem Cell Res Ther 6: 360. doi: 10.4172/2157-7633.1000360

Page 3 of 9

fluorescent microscope (Olympus BX50F4, No. 7M03285, Tokyo, Japan), Biochemistry department, Faculty of medicine, Zagazig University, Zagazig, Egypt, to detect and trace the stem cells labeled with PKH26.

\section{Experimental procedure}

Thirty five healthy adult Wistar male albino rats were classified into three groups:

Group1 (Control group): Included 15 rats that subdivided equally into three subgroups:

\section{Subgroup 1a (negative control group): Received no treatment.}

Subgroup 1b (sham operated group): Rats were subjected to sham operation by $2 \mathrm{~cm}$ abdominal incision under general anesthesia and aseptic precautions. Caecum and colon were delivered through the incision and returned back to the abdominal cavity and closure of the abdominal wall was done [5].

Subgroup 1c (vehicle-treated group): Each rat received $0.5 \mathrm{ml}$ of phosphate-buffered saline as a vehicle of stem cells injected in the tail vein

Group 2 (colostomy group): Comprised 10 animals subjected to colostomy operation, rats were sacrificed four weeks after operation [14].

Group 3 (BM-MSCs treated group): Included 10 animals, they were subjected to colostomy operation as in group 2 and after that they treated with undifferentiated BM-MSCs in the tail vein at the dose of $\left(1 \times 10^{6}\right)$ cells that were suspended in $0.5 \mathrm{ml}$ of Phosphate Buffer Saline (PBS). These rats were sacrificed four weeks after the stem cell therapy [19].

At the end of the experiment, the rats were fasted overnight. They were sacrificed with intraperitoneal injection of pentobarbitone sodium $60 \mathrm{mg} / \mathrm{kg}$ body weight and Specimens from different levels of gastro intestinal tract (gastro-esophageal junction, stomach, duodenum, jejunum, ileum and large intestine) were prepared for histological and immunohistochemical examination.

\section{Histological study}

Specimens for light microscopic examination were fixed in $10 \%$ neutral formol saline, processed for paraffin block preparation, cut into $5 \mu \mathrm{m}$ sections and subjected to H\&E staining [20].

\section{Immunohistochemical analysis of synaptophysin}

Immunohistochemical reaction was carried out using the avidinbiotin complex immunoperoxidase system. Serial sections of paraffinembedded specimens were deparaffinized on charged slides. The sections were incubated in $0.1 \%$ hydrogen peroxide for $30 \mathrm{~min}$ to block the endogenous peroxidase and then incubated with the primary antibody. The primary antibody used for synaptophysin was readyto-use rabbit polyclonal antibody (CAT-No. PA1-1043), Thermo Scientific Laboratories, Rockford, IL, USA). The slides were then incubated with the secondary anti-rabbit antibody versal kits (Zymed laboratories) diluted 1:200 for $30 \mathrm{~min}$., staining was completed by incubation with a substrate chromogen called diamiobenzidine (DAB). Mayer's hematoxylin was used as a counterstain. For negative control, the primary antibody was replaced with phosphate buffer solution [21].

\section{Histo-morphometrical analysis}

The image analyzer computer system Leica Qwin 500 (Leica Ltd, Cambridge, UK) at the Image Analyzing Unit of the Pathology
Department, Faculty of Dentistry, Cairo University, Egypt, was used to evaluate area $\%$ of synaptophysin immunoreaction. It was measured using the interactive measure menu. Measuring frame of a standard area equal to $118476.6 \mathrm{~mm}^{2}$ was chosen so that the brown positive immune reaction for synaptophysin could be seen and masked by blue binary colour to be measured. Ten readings from five non-overlapping sections from each rat of all groups were examined.

\section{Statistical analysis}

All data were expressed as mean \pm SD. Statistical analysis was performed using Statistical Package for the Social Sciences (SPSS) software, version 13.00 (Chicago, Illinois, USA). Statistical significance was determined by one-way and two-way analysis of variance for differences between the means of different groups. Further analysis was carried out using the post-hoc test to compare the parameters between the different groups with each other. Probability of $P$ less than 0.05 was considered statistically significant.

\section{Results}

\section{General observations}

The body weight of the colostomy rats was below the body weight of control group and stem cells treated group.

\section{Histological results}

Histological examination of different GIT sections belonging to control subgroups $1 \mathrm{a}, 1 \mathrm{~b}$ and $1 \mathrm{c}$ did not show any histological variations, therefore, results of subgroup la were represented as the control group.

H\&E stained sections of different GIT levels of control group (Figures 1-7) 1A: gastro-oesophageal junction, 1B: stomach, 1C: duodenum, 1D: jejunum, 1E: ileum and 1F: large intestine) showed the normal morphology of myenteric plexus that found between the external longitudinal and internal circular layers of smooth muscles and surrounded by regular connective tissue capsule. It is formed from different shaped and sized neurons having prominent vesicular nuclei

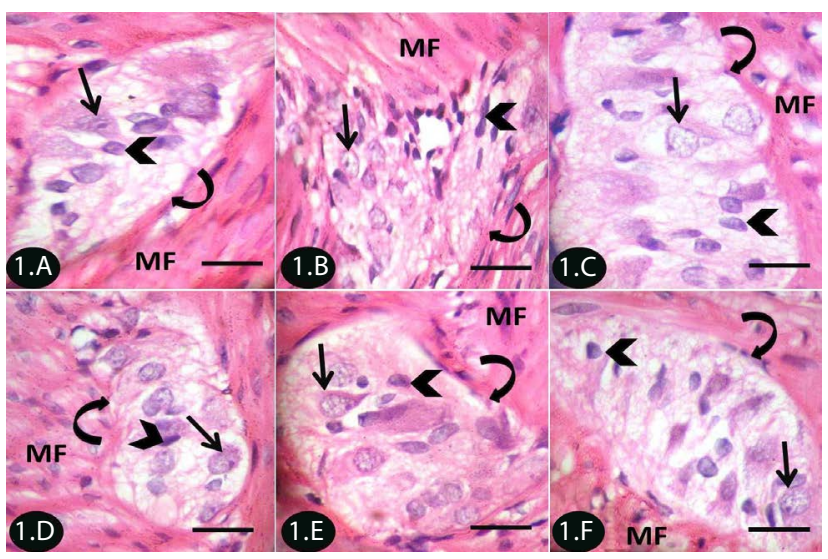

Figure 1: H\&E stained sections of control group from the different levels of gastointestinal tract (A: gastro-oesophageal junction, B: stomach, C: duodenum, $D$ : jejunum, 1.E: ileum and F: large intestine) showing the normal morphology of myenteric plexuses. They are found between two layers of smooth muscle fibers (MF), myenteric plexuses are surrounded by regular connective tissue capsule (curved arrows), formed from different shaped and sized neurons having prominent vesicular nuclei and pale cytoplasm (arrows). Glial cells (arrow heads) are irregularly scattered between neurons or often form wreath around neurons, they have unapparent cytoplasm (H\&E 1000X, scale bar: $20 \mu \mathrm{m}$ ) 
Citation: Ahmed SM, Mohamed DA (2016) Possible Therapeutic Role of Mesenchymal Stem Cells on Colostomy Induced Myenteric Plexus Histological Changes in Different GIT Levels in Adult Male Albino Rats: Histological and Immunohistochemical Study. J Stem Cell Res Ther 6: 360. doi: 10.4172/2157-7633.1000360

Page 4 of 9

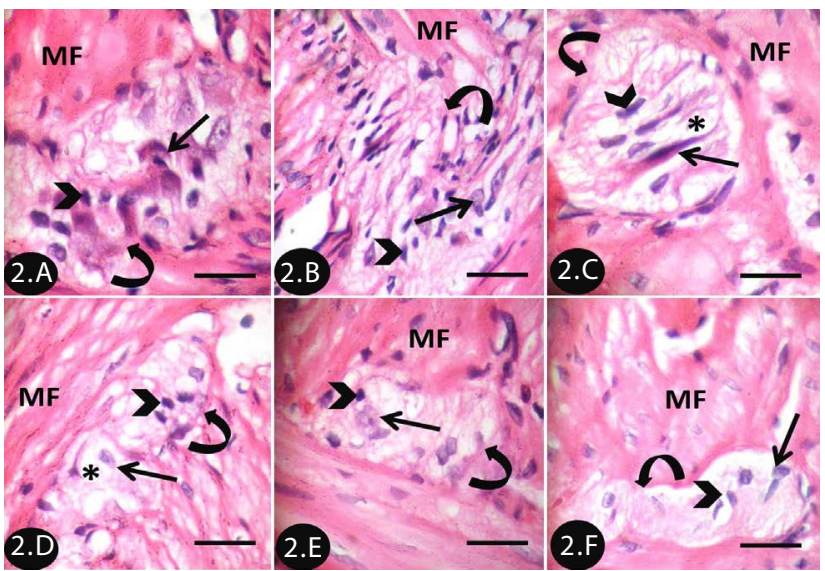

Figure 2: H\&E stained sections of colostomy group from the same levels of gastointestinal tract (A: gastro-oesophageal junction, $\mathrm{B}$ : stomach, $\mathrm{C}:$ duodenum, D:jejunum, E:leum and F:large intestine) showing myenteric plexuses found between layers of smooth muscle fibers (MF), They are surrounded by irregular connective tissue capsule (curved arrows), neurons appear small in size, irregular in shape with small dark nuclei (arrows). Glial cells (arrow heads) are small sized have unapparent cytoplasm and irregularly scattered between neurons. Some sections show wide separation (stars) between cells (H\&E 1000X, scale bar: $20 \mu \mathrm{m}$ ).

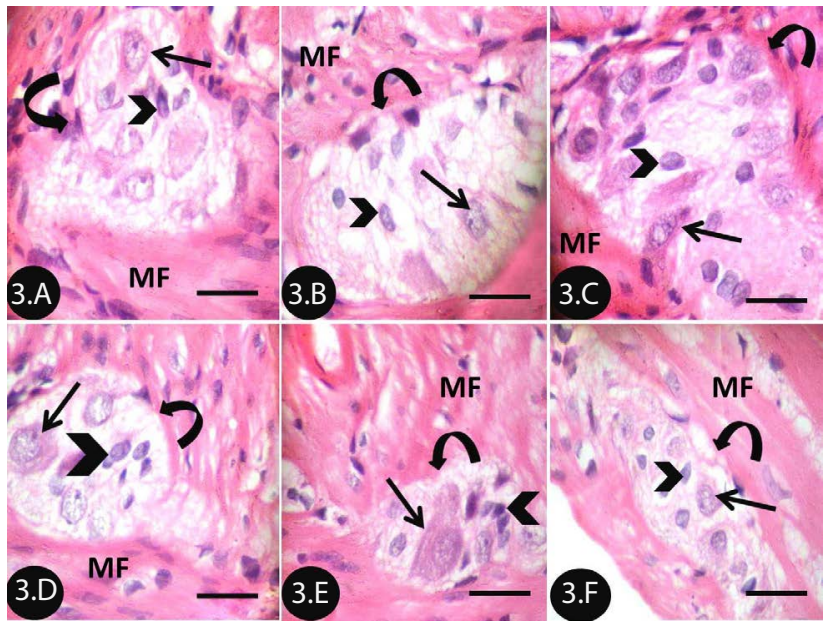

Figure 3: H\&E stained sections of BM-MSCs-treated group from the same different levels of gastointestinal tract (A: gastro-oesophageal junction, B: stomach, C: duodenum, D: jejunum, E: ileum and F: large intestine) showing that the myenteric plexuses preserve their normal structures. They are found between two layers of smooth muscles (MF) and are surrounded by regular connective tissue capsule (curved arrows), containing neurons with vesicular nuclei and pale cytoplasm (arrows). Glial cells (arrow heads) are distributed between neurons, they have unapparent cytoplasm (H\&E 1000X, scale bar: $20 \mu \mathrm{m})$

and pale cytoplasm. Glial cells were irregularly scattered between neurons or often formed wreath around neurons, they had unapparent cytoplasm.

In colostomy group, the same levels of GIT revealed myenteric plexuses with irregular connective tissue capsule. The neurons appeared small in size, irregular in shape with small dark nuclei. Glial cells were small in size and had unapparent cytoplasm and irregularly scattered between neurons. Some sections showed wide separation between cells.

In BM-MSCs treated group, the same levels showed that myenteric plexuses preserved their normal structure. They were found between the two layers of smooth muscles and surrounded by regular connective tissue capsule. The neurons had vesicular nuclei and pale cytoplasm while glial cells were distributed between the neurons with unapparent cytoplasm.

Immunoperoxidase reaction for synaptophysin in the control group showed strong positive immunoreaction in the cytoplasm of neurons in the myenteric plexuses in different GIT levels while in colostomy group, neuronal cytoplasm of myenteric plexuses revealed weak positive immunoreaction. This reaction returned moderate to strong positive in the neurones of BM-MSCs treated group.

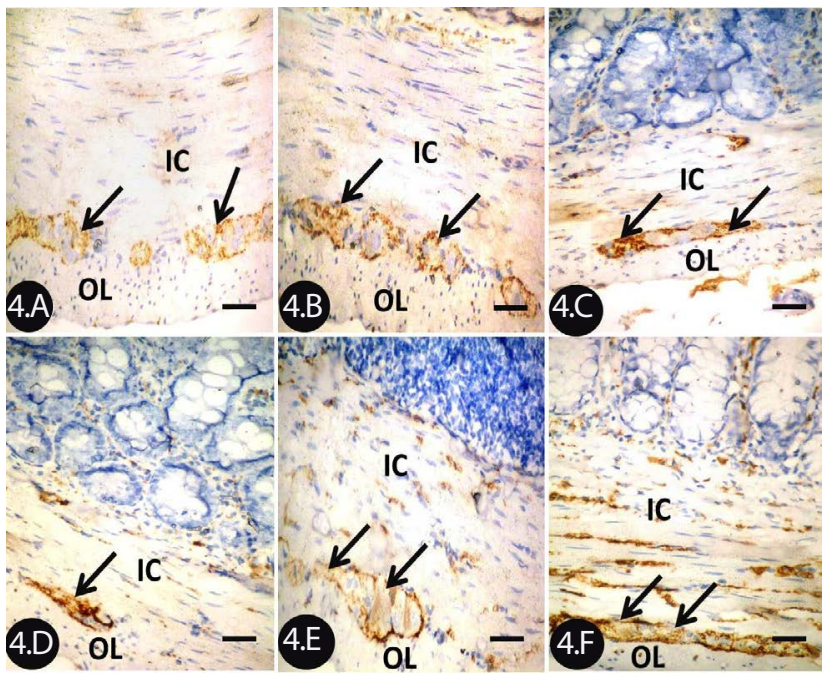

Figure 4: Immunoperoxidase reaction for synaptophysin in sections of contro group from different levels of gastointestinal tract (A: gastro-oesophageal junction, B: stomach, C: duodenum, D: jejunum, E: ileum and F: large intestine) reveals strong positive immunoreaction in the neuronal cytoplasm of myenteric plexuses (arrows) that present between inner circular (IC) and outer longituidinal (OL) layers of smooth muscles. (Immunoperoxidase technique 400X, scale bar: $10 \mu \mathrm{m}$ ).

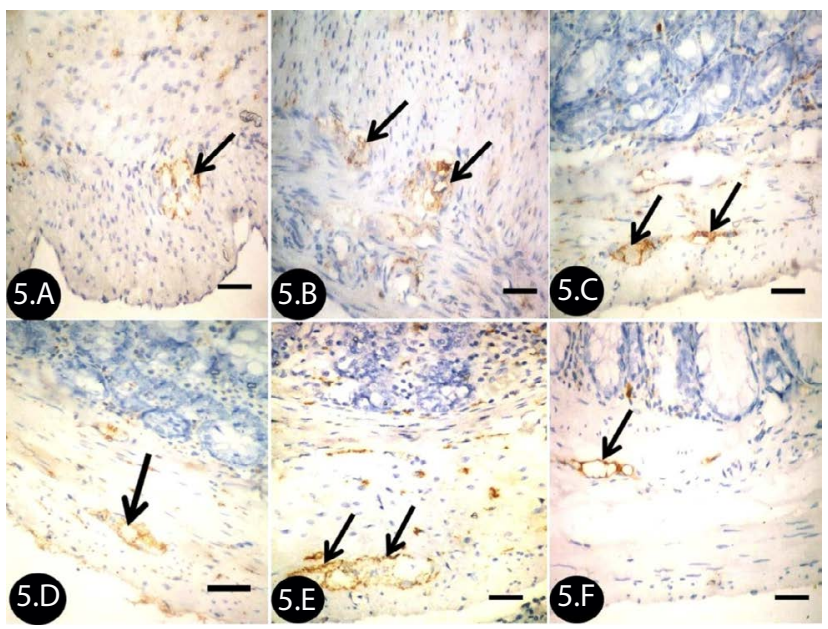

Figure 5: Immunoperoxidase reaction for synaptophysin in sections of colostomy group from the same different levels of gastointestinal tract $(A$ gastro-oesophageal junction, $B$ : stomach, $C$ : duodenum, D: jejunum, $E$ : ileum and $\mathrm{F}$ : large intestine) reveals weak positive immunoreaction in the neuronal cytoplasm of myenteric plexuses (arrows) (Immunoperoxidase technique $400 \mathrm{X}$, scale bar: $10 \mu \mathrm{m}$ ) 
Citation: Ahmed SM, Mohamed DA (2016) Possible Therapeutic Role of Mesenchymal Stem Cells on Colostomy Induced Myenteric Plexus Histological Changes in Different GIT Levels in Adult Male Albino Rats: Histological and Immunohistochemical Study. J Stem Cell Res Ther 6: 360. doi: 10.4172/2157-7633.1000360

Page 5 of 9

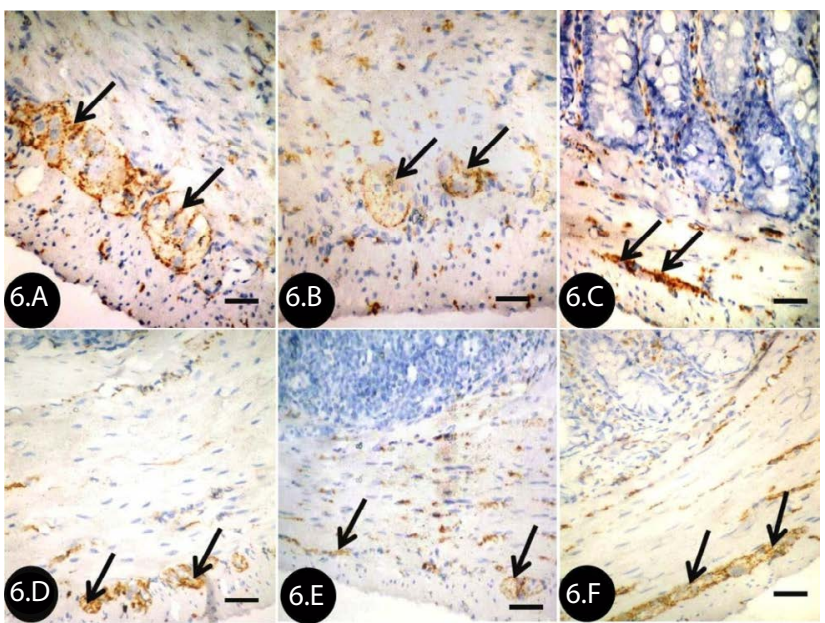

Figure 6: Immunoperoxidase reaction for synaptophysin in sections of BMMSCs-treated group from the same different levels of gastointestinal tract (A: gastro-oesophageal junction, B: stomach, C: duodenum, D: jejunum, E: ileum and F: large intestine) reveals moderate to strong positive immunoreaction in the neuronal cytoplasm of myenteric plexuses (arrows) (Immunoperoxidase technique 400X, scale bar: $10 \mu \mathrm{m}$ )

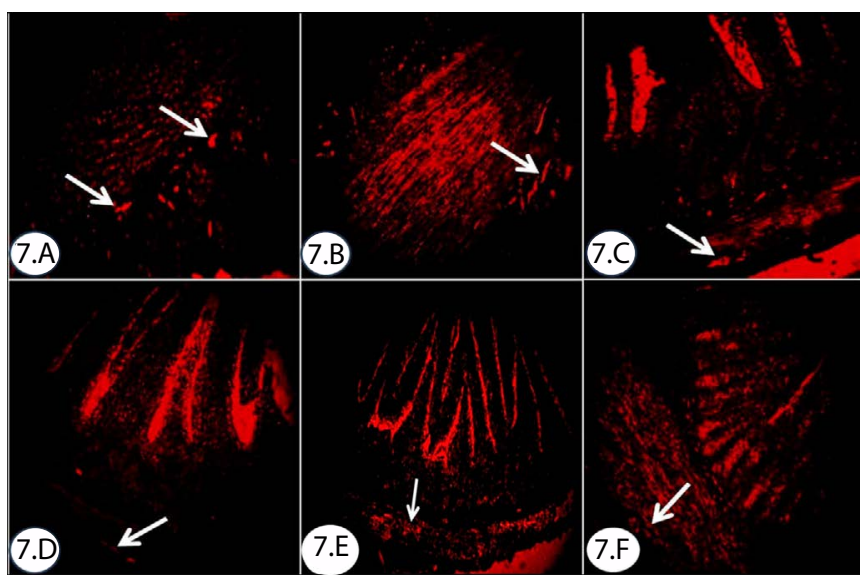

Figure 7: Sections of BM-MSCs treated group in different levels of gastointestinal tract (A: gastro-oesophageal junction, B: stomach, C: duodenum, D: jejunum, E: ileum and F: large intestine) showing $\mathrm{PKH} 26$ labled cells that appear as bright red dots in the myenteric plexuses (arrows) between smooth muscle fibers (Flourescent microscope 200X).

Additionally, fluorescent microscope examination revealed PKH26 labeled cells that appeared as bright red dots in the myenteric plexuses between smooth muscle fibers in all groups.

\section{Histo-morphometrical and statistical results}

Statistically significant decrease in the mean body weight of albino rats was detected in colostomy group as compared to the control group and BM-MSCs treated group. No statistically significant difference between the control group and BM-MSCs treated group (Table 1 and Figure 8).

Highly statistically significant decrease in the mean area percent of synaptophysin immunoreaction was detected in different GIT levels of colostomy group as compared to the same levels in control and BMMSCs treated groups. No statistically significant difference between the control group and BM-MSCs treated group (Tables 2-7 and Figures 9-14).

\section{Discussion}

GIT achieves a remarkable variety of functions, such as transport of luminal content, secretion and absorption of ions, water and nutrients, defense against pathogens and elimination of waste and/or noxious substances. Digestive functions are regulated by a complex neural network, known as ENS, endowed in the gut wall and extending throughout its length from the esophagus to the internal anal sphincter [22].

Normal function of the gastrointestinal tract is dependent on the interaction of ENS, the smooth muscle and the submucosal and mucosal layer of its wall. The ENS could be used to study the neuronal plasticity due to its easy access. Besides, it is also used to study the role that nervous plexuses play in their different intestinal functions. It is

\begin{tabular}{|c|c|c|c|}
\hline Parameter & Mean \pm SD & F & P-value \\
\hline G1 & $235.9 \pm 3.2$ & & $<0.01^{*}$ \\
\hline G2 & $160.02 \pm 1.78$ & 119.8 & \\
\hline G3 & $220.6 \pm 4.13$ & & \\
\hline \multicolumn{3}{|c|}{ GS for comparison between groups } \\
\hline G2 & $<0.01^{*}$ & G2 \\
\hline G3 & $>0.05$ & $<0.01^{*}$ \\
\hline
\end{tabular}

*Significant

Table 1: The mean body weight of rats in different studied groups.

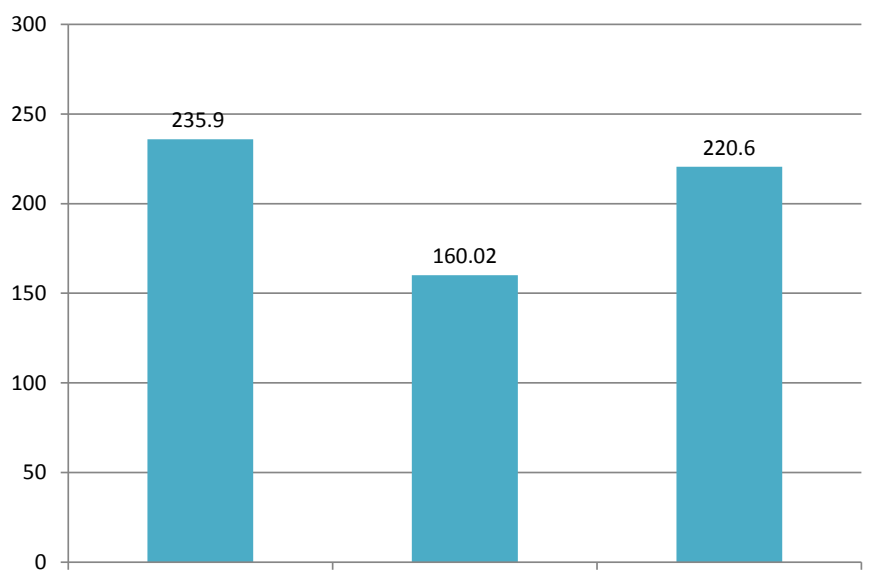

G1

G2

Figure 8: The mean body weight of rats in different studied groups.

\begin{tabular}{|c|c|c|c|}
\hline \begin{tabular}{|l|} 
Parameter \\
\\
Group
\end{tabular} & Mean \pm SD & $\mathbf{F}$ & P-value \\
\hline G1 & $60.1 \pm 11.5$ & \multirow{3}{*}{123.006} & \multirow{3}{*}{$<0.01^{* *}$} \\
\hline G2 & $19.4 \pm 0.9$ & & \\
\hline G3 & $57.9 \pm 0.9$ & & \\
\hline \multicolumn{4}{|c|}{ LSD for comparison between groups } \\
\hline & G1 & \multicolumn{2}{|c|}{ G2 } \\
\hline G2 & $<0.01^{* *}$ & & \\
\hline G3 & 0.481 & \multicolumn{2}{|c|}{$<0.01^{* *}$} \\
\hline
\end{tabular}

**Highly Significant

Table 2: Area percent of synaptophysin immunoreaction in gastro-esophageal junction. 
Citation: Ahmed SM, Mohamed DA (2016) Possible Therapeutic Role of Mesenchymal Stem Cells on Colostomy Induced Myenteric Plexus Histological Changes in Different GIT Levels in Adult Male Albino Rats: Histological and Immunohistochemical Study. J Stem Cell Res Ther 6: 360. doi: 10.4172/2157-7633.1000360

Page 6 of 9

\begin{tabular}{|c|c|c|c|}
\hline Parameter & Mean \pm SD & F & P-value \\
\hline G1 & $61.3 \pm 0.9$ & & $<0.01^{* *}$ \\
\hline G2 & $22.7 \pm 0.9$ & 5151.231 & \\
\hline G3 & $54.9 \pm 0.8$ & \\
\hline LSD for comparison between groups \\
\hline G2 & $\mathbf{G 1}$ & $\mathbf{G 2}$ \\
\hline G3 & 0.351 & $<0.01^{\text {** }}$ \\
\hline
\end{tabular}

**Highly Significant

Table 3: Area percent of synaptophysin immunoreaction in stomach.

\begin{tabular}{|c|c|c|c|}
\hline Parameter & Mean \pm SD & F & P-value \\
\hline G1 & $58.2 \pm 0.9$ & & $<0.01^{* *}$ \\
\hline G2 & $28.01 \pm 0.9$ & 2999.858 & \\
\hline G3 & $51.2 \pm 0.8$ & \\
\hline LSD for comparison between groups \\
\hline G2 & G1 & G2 \\
\hline G3 & 0.279 & $<0.01^{* *}$ \\
\hline
\end{tabular}

**Highly Significant

Table 4: Area percent of synaptophysin immunoreaction in duodenum

\begin{tabular}{|c|c|c|c|}
\hline Parameter & Mean \pm SD & F & P-value \\
\hline G1 & $56.8 \pm 0.9$ & \multirow{2}{*}{4245.25} & $<0.01^{* *}$ \\
\hline G2 & $21.5 \pm 0.9$ & & \\
\hline G3 & $50.5 \pm 0.8$ & \\
\hline \multicolumn{3}{|c|}{ Group } & G2 \\
\hline G2 & $<0.01^{* *}$ & $<0.01^{\text {** }}$ \\
\hline G3 & 0.120 & \\
\hline
\end{tabular}

**Highly Significant

Table 5: Area percent of synaptophysin immunoreaction in jejunum.

\begin{tabular}{|c|c|c|c|}
\hline $\begin{array}{l}\text { Parameter } \\
\text { Group }\end{array}$ & Mean \pm SD & $\mathbf{F}$ & P-value \\
\hline G1 & $56.9 \pm 0.9$ & \multirow{3}{*}{4663.604} & \multirow{3}{*}{$<0.01^{* *}$} \\
\hline G2 & $19.8 \pm 0.8$ & & \\
\hline G3 & $49.9 \pm 0.9$ & & \\
\hline \multicolumn{4}{|c|}{ LSD for comparison between groups } \\
\hline & G1 & \multicolumn{2}{|c|}{ G2 } \\
\hline G2 & $<0.01^{* *}$ & & \\
\hline G3 & 0.406 & \multicolumn{2}{|c|}{$<0.01^{* *}$} \\
\hline
\end{tabular}

**Highly Significant

Table 6: Area percent of synaptophysin immunoreaction in ileum.

\begin{tabular}{|c|c|c|c|}
\hline Parameter & Mean \pm SD & F & P-value \\
\hline G1 & $57.2 \pm 0.8$ & \multirow{2}{*}{4532.002} & $<0.01^{* *}$ \\
\hline G2 & $20.04 \pm 0.9$ & & \\
\hline G3 & $48.4 \pm 0.8$ & \\
\hline \multicolumn{3}{|c|}{$\mathbf{~ G 2}$} \\
\hline LSD for comparison between groups \\
\hline G3 & $\mathbf{G 1}$ & \\
\hline
\end{tabular}

**Highly Significant

Table 7: Area percent of synaptophysin immunoreaction in large intestine.

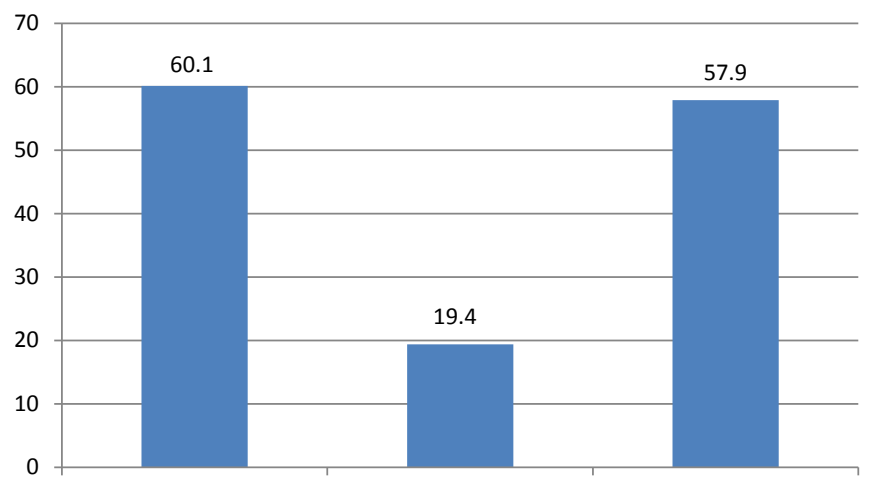

G1

G2

Figure 9: Area percent of synaptophysin immunoreaction in gastroesophageal junction.

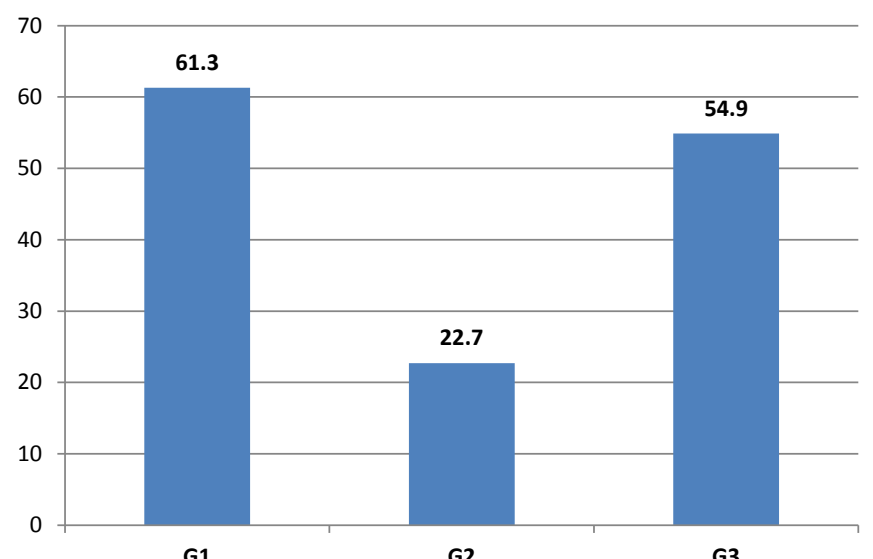

Figure 10: Area percent of synaptophysin immunoreaction in stomach.

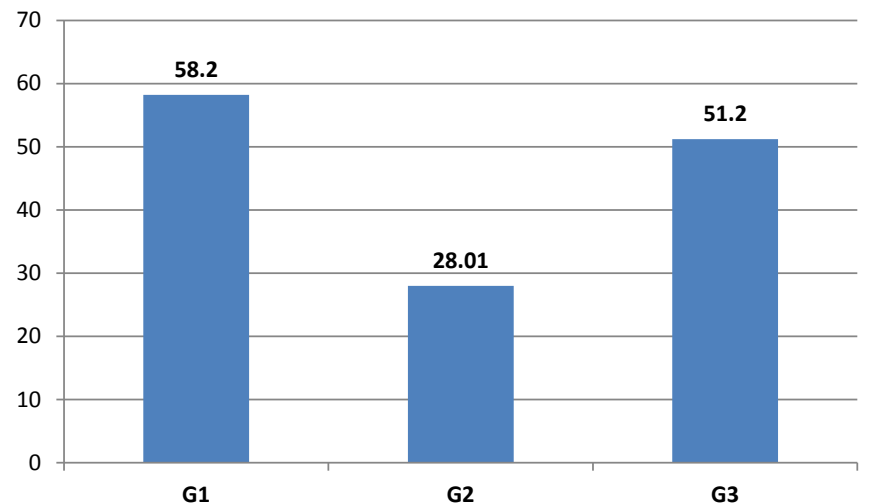

Figure 11: Area percent of synaptophysin immunoreaction in duodenum.

complex and its complexity is reflected on the diversity of neurons and the existence of a wide range of neurotransmitters that are found and act in neurons $[1,23]$.

Neurons of the enteric system play a vital role in coordinating the activities of other gastrointestinal cells and control the processes such as absorption, secretion, and microvasculature. Recent evidence shows that the enteric neurons influence the function of the epithelial barrier 
Citation: Ahmed SM, Mohamed DA (2016) Possible Therapeutic Role of Mesenchymal Stem Cells on Colostomy Induced Myenteric Plexus Histological Changes in Different GIT Levels in Adult Male Albino Rats: Histological and Immunohistochemical Study. J Stem Cell Res Ther 6: 360. doi: 10.4172/2157-7633.1000360

Page 7 of 9

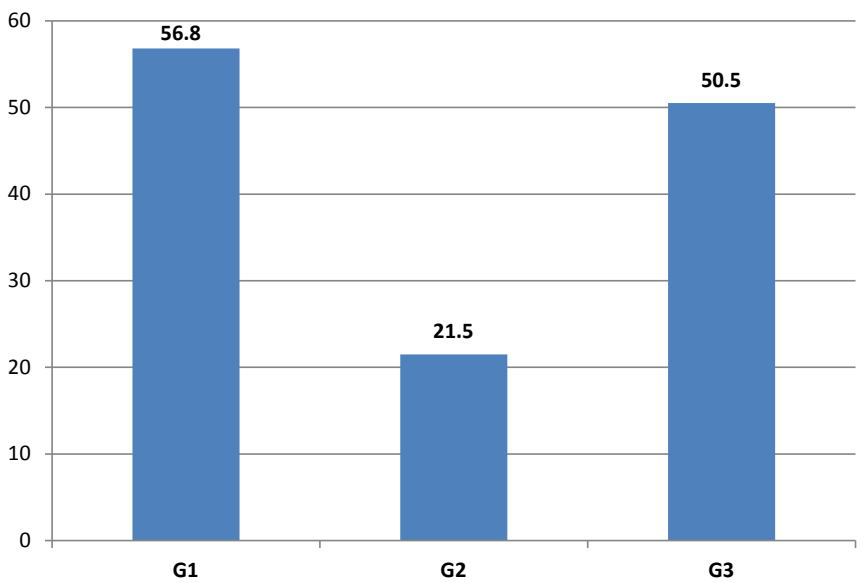

Figure 12: Area percent of synaptophysin immunoreaction in jejunum

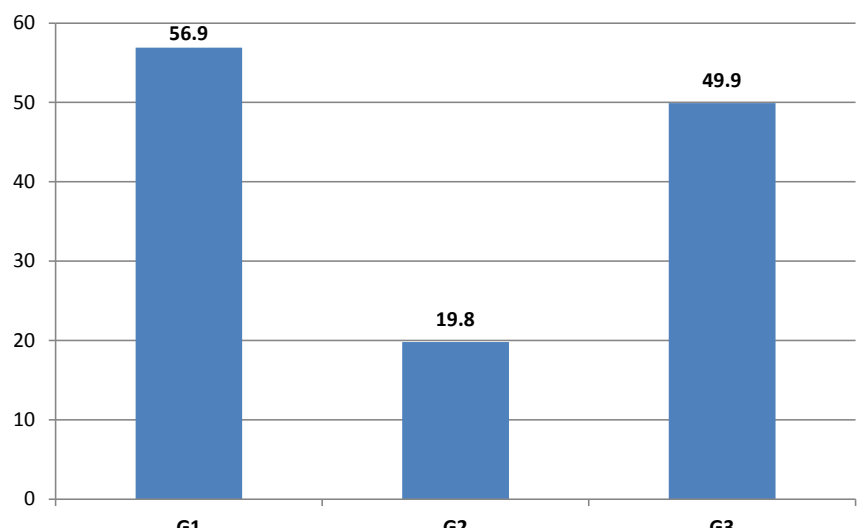

Figure 13: Area percent of synaptophysin immunoreaction in ileum.

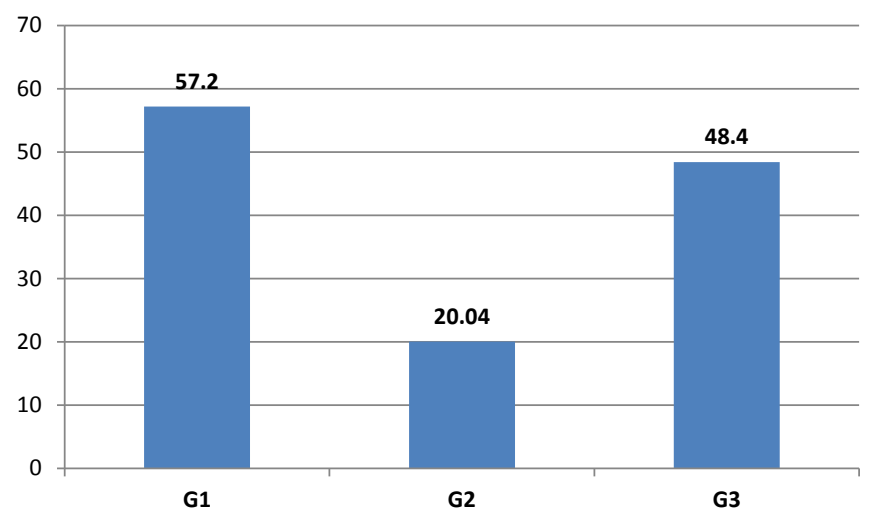

Figure 14: Area percent of synaptophysin immunoreaction in large intestine.

[23]. Myenteric plexus mainly regulates motility, and submucosal plexus mainly regulates secretion and local blood flow [24].

In present work, myenteric plexus of colostomy group appeared with irregular CT capsule and had wide separations between the cells. Neuronal cells were few in number and had small dark nuclei. They were irregular in shape and small in size. Similar results detected by Rice et al. [25] who record loss and decrease neuronal cells in chronic myenteric plexus inflammation. The ENS has special interest because it is the only generous grouping of neurons outside the central nervous system that form circuits capable of autonomous reflex activity. In humans, it contains around 500 million neurons that fall into about 20 functional classes. Its size, complexity, and certain structural similarities make it as second brain of the gut [26].

In the current work, glial cells were small in size and had unapparent cytoplasm and irregularly scattered between neurons. Some sections showed separation between the cells. Saffery [27] reported similar cellular changes in myenteric plexus during aging and emphasized our results as regard to glial cells. They observed significant loss of enteric glial (expressed as counts per ganglion and per ganglionic area) in all areas except the rectum. The glial cell loss was also found to be proportional to the neuronal loss in this study.

Two main cell populations are represented in the ENS, neurons and enteric glial cells (EGC), the latter being much more abundant (up to fourfold) than neurons. They function as simple mechanical support and also important for the homeostasis of the gut, including influence on motility and inflammatory processes $[28,29]$.

Bassotti [30] reported that reduced number of EGC, together with the decrease or loss of other ENS cell populations may play a role in GIT diseases. Reduced number of interstitial cells of Cajal impairs the pacemaker enteric signals and might lead to an abnormal neurotransmission secondary to the diminished the number of enteric neurons, and deteriorated by an impairment of EGC. The loss of the properties of these cell populations could lead to GIT dysmotilities. Several mechanisms involved as impairment of mechanical properties of the plexuses, decreased gut neurotransmission, and reduced homeostatic support to the enteric neurons. All these conditions could lead to neurodegeneration and/or phenotypic shift, even in the absence of inflammation $[31,32]$.

Moreover, BM-MSCs-treated group in the same levels revealed that myenteric plexuses preserved their normal structure. They were found between two layers of smooth muscle and surrounded by regular connective tissue capsule. The neurons had vesicular nuclei and pale cytoplasm while glial cells were distributed between neurons with unapparent cytoplasm. Metzger [33] observed the same results when they used stem cells to cure aganglionic gut disorders. They concluded that the gut mucosa has potentiality as a source of ENS stem cells and could be used as practical enteric neural transplantation treatments for several ENS disorders such as HSCR. They added that these cells have the capability for the establishment of neural components within the many facets of regenerative medicine.

Neural stem cell therapies have emerged as a real prospect of cure. Stem cells are large, primitive cells that do not express markers of lineage differentiation, and also are consequently difficult to define and characterize morphologically. Stem cells provide the fundamentals of every organ in the body, with their ability for self-renewal by symmetrical division and their ability to generate the entire adult cell component within their indigenous tissue via asymmetrical cell division. Stem cells function to regulate the rate of cell production in a tissue to maintain homeostasis, and can upregulate cell turnover concurrent to increasing regenerative response dictated by damage or disease.

Schafer et al. [34] investigated the role of stem cell of different origins to replace the cells of ENS in damaged GIT segments. They utilized either hemopoietic of embryonic stem cells to replace diseased cells and confirmed their ability for restoration of ENS function in the 
Citation: Ahmed SM, Mohamed DA (2016) Possible Therapeutic Role of Mesenchymal Stem Cells on Colostomy Induced Myenteric Plexus Histological Changes in Different GIT Levels in Adult Male Albino Rats: Histological and Immunohistochemical Study. J Stem Cell Res Ther 6: 360. doi: 10.4172/2157-7633.1000360

Page 8 of 9

aganglionic gut. Now, it is feasible to use neural stem cell (NSC) transplantation to restore ENS function in diseased segments of the gut.

In vivo studies have shown that ENS stem cells not only have the ability to migrate, proliferate and differentiate when transplanted into the colon of postnatal mice, but that they display morphological, neurochemical and electrophysiological properties typical of enteric neurons, such as synaptic inputs and neurite projections to muscle layers and intrinsic ganglia [35].

Synaptophysin $(38 \mathrm{kDa})$ is an important membrane protein found in the nerve ending at synapses. This protein occurs in neurotransmitter containing small synaptic vesicles, located inside the presynaptic terminals and is suggested to have an active involvement in the regulation of vesicular exocytosis [36]. In current study, immunoperoxidase reaction for synaptophysin revealed weak positive immunoreaction in the neuronal cytoplasm of myenteric plexuse of colostomy group. This reaction returned moderate to strong positive in the cytoplasm of neurones of BM-MSCs-treated group. This protein is considered as index of specific neuronal function. Immunoreactivity for this protein reduced markedly in several GIT diseases. Also, aggregation of alpha-synuclein (a-syn) has been implicated also in the development of neurodegenerative diseases. Physiologically, a-syn is located at the presynapse and might be involved in regulating of neurotransmission [37].

Additionally, fluorescent microscope examination revealed PKH26 labled cells that appeared as bright red dots in the myenteric plexuses between smooth muscle fibers in BM-MSCs treated group. During the last decade, ENS has coming into focus of clinical Neuronal Stem Cell Therapy (NSCT) [34]. Current therapeutic options for many ENS disorders are inadequate and limited to palliative interventions aimed to prevent mortality, control symptoms and prevent complications. They are not aimed to replace or replenish dysfunctional or missing neural components of the ENS. Over the past decade, identification and study of NSC opens up the possibility of definitive curative therapies for these disorders [38].

The ENS has many potential advantages that encourage the success of cellular transplantation therapies. These advantages include ease of accessibility to both the source of the cells and then delivery of the transplant, as well as the possibility of minimizing immunological rejection by growing neural stem cells obtained from unaffected regions of the patient's own intestine for autologous transplantation $[38,39]$.

This perspective article aims to evaluate the progress that has been made in ENS neuropathies due to a lack of effective treatments. Over the past decade, stem cell therapies have emerged as a real prospect of cure in many diseases. The use of this therapy for restoration of the function of ENS is feasible. So, this work has suggested possible pathways to clinical and early trials that provide direction for the needed further research. Also, it has recommended by more fundamental research in this field that is clearly required as progress in this new and very exciting therapeutic road.

\section{References}

1. Khen-Dunlop N, Sarnacki S, Victor A, Grosos C, Menard S, et al. (2013) Prenatal intestinal obstruction affects the myenteric plexus and causes functional bowel impairment in fetal rat experimental model of intestinal atresia. PLoS One 8: 1-13. [PubMed]

2. Nezami B, Srinivasan S (2010) Enteric nervous system in the small intestine: pathophysiology and clinical implications.Curr Gastrointestinal Rep 12: 358365. [PubMed]
3. Villanacci V, Bassotti G, Nascimbeni R, Antonelli E, Cadei M, et al. (2008) Enteric nervous system abnormalities in inflammatory bowel diseases. Neurogastroenterol. Motil 20: 1009-1016. [PubMed]

4. United Ostomy Associations of America, Inc. (2014) What is an Ostomy? Accessed www.ostomy.org/What_is_an_Ostomy.html

5. Chaudhury A, Shariff A, Srinivas M, Sabherwal U (2004) Changes in nitrergic innervations of defunctionalized rat colon after diversion colostomy. Neurogastroenterol Motil 16: 475-487. [PubMed]

6. Silva MA, Ratnayake G, Deen KI (2003) Quality of life of stoma patients: temporary ileostomy vs colostomy. World J Surg 27: 421-424. [PubMed]

7. Szczepkowski M (2002) Do we still need a permanent colostomy in XXI-st century? Acta Chir lugosl 49: 45-55. [PubMed]

8. Kilic E, Taycan O, Belli A, Ozmen M (2007) The effect of permanent ostomy on body image, self esteem, marital adjustment and sexual functioning. Turk Psikiyatri Dergisi 18: 1-8. [PubMed]

9. Vries R, Huch M, Clevers $H$ (2010) Stem cells and cancer of the stomach and intestine. Review Mol Oncol 4: 373-384. [PubMed]

10. Brittan M, Wright N (2015) Stem cell in gastrointestinal structure and neoplastic development. Gut 53: 899-910. [PubMed]

11. Martinez-Montiel M, Gomez-Gomez G, Flores A (2014) Therapy with stem cells in inflammatory bowel disease. World Gastroenterol 20: 1211-1227. [PubMed]

12. Pinto FEL Jr, Oliveira AJF, Medeiros KF, Ramos AMO, Ramos CCO, et al. (1999) Repercussões histopatológicas da colostomia no coto colônico distal desfuncionalizado: estudo experimental em ratos. Rev Col Bras Cir 26: 327 333.

13. Araújo FI, Honorato SAA, Rego ACM, Garcia ACMA, Fernandes DP, et al (2006) Influence of laparoscopy and laparotomy on gasometry, leukocytes and cytokines in a rat abdominal sepsis model. Acta Cir Bras 21: 74-79.

14. de Oliveira AF, Junior F, Formiga M, Melo S, Brandao-Neto J, et al. (2010) Comparison of prophylactic and therapeutic uses of short-chain fatty acid enemas in diversion colitis: a study in Wistar rats. Clinics 65: 1351-1356. [PubMed]

15. Alhadlaq A, Mao J (2004) Mesenchymal stem cells: isolation and therapeutics. Stem Cells Dev 13: 436-448. [PubMed]

16. Zhang L, Zhang Q, Qian J (2010) The culture method and biologica characteristics of rabbit mesenchymal stem cells derived from bone marrow in vitro. Prog Mod Biomed 813: 1307.

17. Haasters F, Prall W, Anz D, Bourquin C, Pautke C, et al. (2009) Morphological and immunocytochemical characteristics indicate the yield of early progenitors and represent a quality control for human mesenchymal stem cell culturing. $J$ Anat 214: 759-767. [PubMed]

18. Haas SJ, Bauer P, Rolfs A, Wree A (2000) Immunocytochemical characterization of in vitro PKH26-labelled and intracerebrally transplanted neonatal cells. Acta Histochem 102: 273-280. [PubMed]

19. Cho YB, Kim MS, Kang MJ, Shin HJ, Kim SH, et al. (2010) Immunomodulatory Effects of Mesenchymal Stem Cells in a Murine Model of TNBS Induced Colitis. J Korean Surg Soc 79: 317-325.

20. Bancroft J, Layton C (2013) Hematoxylin and eosin. In: Suvarna SK, Layton $\mathrm{C}$ and Bancroft JD (ed). Theory and Practice of histological techniques. $7^{\text {th }}$ edition. Churchill Livingstone of El Sevier, Philadelphia pp: 172-214.

21. Vara JAR, Kiupel M, Baszler T, Bliven L, Brodersen B, et al. (2008) Suggested guidelines for immunohistochemical techniques in veterinary diagnostic laboratories. J Vet Diagn Invest 20: 393-413. [PubMed]

22. Bagyanszki M, Bodi N (2012) Diabetes- related alterations in the enteric nervous system and its microenvironment. World J Diabetes 3: 80-93. [PubMed]

23. Buttow N, Santin M, Macedo L, Teixeira A, Novakowski G, et al. (2004) Study of the myenteric and submucous plexuses after BAC treatment in the intestine of rats. Biocell 28: 135-142. [PubMed]

24. Zhou Y, Yang J, Watkins D, Boomer L, Matthews M, et al. (2013) Enteric nervous system abnormalities are present in human necrotizing enterocolitis: potential neurotransplantation therapy. Stem cell Res Ther 4: 1-13. [PubMed]

25. Rice T, Goldblum J, Yearsley M, Shay S, Reznik S, et al. (2009) Myenteric plexus abnormalities associated with epipheric diverticula. Eur J Cardiothorac Surg 35: 22-27. [PubMed] 
Citation: Ahmed SM, Mohamed DA (2016) Possible Therapeutic Role of Mesenchymal Stem Cells on Colostomy Induced Myenteric Plexus Histological Changes in Different GIT Levels in Adult Male Albino Rats: Histological and Immunohistochemical Study. J Stem Cell Res Ther 6: 360. doi: 10.4172/2157-7633.1000360

Page 9 of 9

26. Mandic P, Lestarevic S, Filipovic T, Savic S, Stevic S, et al. (2015) Age-related changes in the myenteric plexus of the human jejunum. Folia Morphol (Warsz) 1-21. [PubMed]

27. Saffrey $M(2013)$ Cellular changes in the enteric nervous system during aging Develomental Biology 382: 344-355. [PubMed]

28. Lomax AE, Fernandez E, Sharkey KA (2005) Plasticity of the enteric nervous system during intestinal inflammation. Neurogastroenterol Motil 17: 4-15. [PubMed]

29. Von Boyen GB, Steinkamp M, Reinshagen M, Schafer KH, Adler G, et al. (2004) Proinflammatory cytokines increase glial fibrillary acidic protein expression in enteric glia. Gut 53: 222-228. [PubMed]

30. Bassotti G, Villanacci V, Fisogni S, Rossi E, Baronio P, et al. (2007) Enteric glial cells and their role in gastrointestinal motor abnormalities: introducing the neuro-gliopatheis. World J gastroenterol 13: 4035-4041. [PubMed]

31. Ruhl A (2005) Glial cells in the gut. Neurogastroenterol Motil 17: 777-790. [PubMed]

32. Ruhl A (2006) Glial regulation of neuronal plasticity in the gut: implications for clinicians. Gut 55: 600-602. [PubMed]
33. Metzger M, Caldwell C, Barlow A, Burns A, Thapar N (2009) Enteric nrvous system stem cells derived from human gut mucosa for the treatment of aganglionic gut disorders. Gastroenterol 136: 2214-2225. [PubMed]

34. Schafer K, Micci M, Pasricha P (2009) Neuronal stem cell transplantation in the enteric nervous system: roadmaps and roadblocks. Neurogastroenterol. Motil 21: 103-112. [PubMed]

35. Hotta R, Stamp LA, Foong JPP, McConnell SN, Bergner AJ, et al. (2013) Transplanted progenitors generate functional enteric neurons in the postnatal colon. J Clin Invest 123: 1182-1191. [PubMed]

36. Jahn R, Sudhof T (1994) Synaptic vesicles and exocytosis. Annu Rev Neurosci 17: 219-246. [PubMed]

37. Asar M, Bayram Z, Korgun E, Tertemiz F, Akkoyunlu G, et al. (2004) Immunocytochemical detection of synaptophysin in enteric neurons during prenatal development in rat stomach. Anat Histol Embryol 33: 135-140. [PubMed]

38. Burns A, Thapar N (2014) Neuronal stem cell therapies for enteric nervous disorders. Nat Rev Gastroenterol Hepatol 11: 317-328. [PubMed]

39. Schafer K, Ginneken C, Copray S (2009) Plasticity and neural stem cells in the enteric nervous system. Anat Rec 292: 1940-1952. [PubMed] 